\title{
Os espaços de leitura
}

Angela Maria Barreto

Doutora em Ciência da Comunicação pela ECA/USP.

Professora adjunta do Instituto de Ciência da Informação da UFBA.

E-mail: ambar@ufba.br

A compreensão do ato de ler é complexa e exige articulação com muitos aspectos lingüísticos, cognitivos, socioculturais imbricados no processo de construção de sentidos. Leitura tem caráter existencial, não é ato meramente técnico ou pragmático, esvaziado de sentidos. Em trabalho anterior ${ }^{1}$, elencamos alguns elementos que consideramos essenciais à prática da leitura, vista sob o prisma da significação. Podemos apresentá-los sem, contudo, aprofundarmos suas colocações, mas apenas para que introduzam nossas reflexões:

1) Singularidade - a leitura particulariza o sujeito.

2) Alteridade - a leitura colabora na construção do sujeito como um outro, sua maneira de se relacionar com o outro, e auxilia na formação de vínculos.

3) Identidade - a leitura possui papel fundamental na constituição da noção de pertencimento do sujeito ao grupo social.

4) Tempo - o tempo dedicado à leitura tem dimensão social e individual e significação para a constituição de uma forma particular de o sujeito significar o mundo.

5) Leitura e Classe Social - classes sociais distintas imputam diferentes valores à leitura.

6) Leitura, Informação e Conhecimento - leitura é ferramenta útil ao trabalho, ao desenvolvimento profissional, ao acesso à informação, à construção do conhecimento, portanto, ligada à questão econômica e à luta pela inserção social.

7) Instituições de Leitura - constituem elementos essenciais para a consolidação do leitor.

8) Espaço de Leitura - mostra a relação do leitor com os espaços e suas dimensões.

Aqui nos deteremos. Espaço da Leitura é o fio condutor de nossa discussão, daqui em diante. Trata-se de categoria que vai articular espaço real e imaginário e apontar a ação do sujeito, que se expressa durante o ato de ler como parte da ordenação do seu mundo mental, sendo também maneira própria de modelar o mundo.

Há uma correspondência entre ler num tempo e ler num espaço, intrínseca ao ato de ler. São comuns os testemunhos de leitores que falam dos lugares escolhidos para leitura, sendo muitos deles estranhos para alguns de nós.

No começo da Idade Média eram comuns as reuniões em casas de autores, para leitura coletiva de suas criações. Eram lidas em voz alta. Reunir-se para

1. BARRETO, Angela Maria. Memória de leituras: trajetória de leitores idosos do Vale do Paraíba - Uma contribuição aos estudos da relação entre informação e produção de sentidos. Dissertação (Doutorado). São Paulo: CBD/ECA/USP, 2003. 
2. MANGUEL, Alberto. Uma história da leitura. 3. ed. São Paulo: Companhia das Letras, 1997. p. 281.

3. ARIÉS, Philippe; DUBY, Georges. História da vida privada: da Renascença ao século das luzes. São Paulo: Companhia das Letras, 1991. v. 3.

4. CHARTIER, Roger. Do livro à leitura. In: Práticas da leitura. São Paulo: Estação Liberdade، 2001. p. 9-18.

5. ARIÉS e DUBY, op. cit.

6. Ibid., p. 136-147.

7. PEREIRA, Taís Assunção Curi. Informação e conhecimento. Revista de Estudos e Comunicações Leopoldianum, Santos: EDUL, n. 77, p. 4, 2002. ouvir os autores e "as leituras públicas tornaram-se quase inevitáveis para quem quisesse ser conhecido como autor"'. Nos mosteiros, lia-se, normalmente, à hora das refeições. Um leitor semanal era escolhido e devia preparar-se para tal missão. O espaço de leitura era o refeitório. Na sociedade moderna já se notam alterações no ambiente onde a leitura é realizada.

Ao referirem-se às práticas de leitura do começo da Idade Moderna, Ariés ${ }^{3}$ e Chartier ${ }^{4}$ falam da leitura silenciosa como marca importante dos tempos, que, além de conferir à espiritualidade um tom de maior privacidade, propiciou audácias que não eram permitidas, como ler na cama, no banheiro, num sofá, ou solitariamente. A prática da leitura silenciosa, olhos perscrutando as letras, foi iniciada pelos copistas dos monastérios, estendendo-se aos aristocratas e, a partir do século XV, tornou-se a maneira usual de ler, transformando a essência do trabalho intelectual, que passou a ser um ato de intimidade individual ${ }^{5}$. Na modernidade, a prática da leitura foi privatizada, o que não quer dizer que os espaços coletivos de leitura, comuns na Idade Média, tenham sido totalmente substituídos pelos íntimos. A leitura coletiva permaneceu como prática.

A partir dos séculos XVII e XVIII, vê-se outro aspecto dessas leituras no interior das casas, em gabinetes e locais privativos, e a manipulação dos textos e outras práticas sendo engendradas. Essas características impõem novas maneiras de percepção da realidade: a língua em ação e os ouvidos perscrutando, modificando, inclusive, o próprio trabalho intelectual. Mas não só o trabalho intelectual é alterado pelas práticas da leitura, como a própria maneira de modular o mundo é modificada. Não se praticavam as leituras apenas em grandes gabinetes ou na intimidade da alcova. Lidas em voz alta, constituíam divertimentos da vida privada. $\mathrm{O}$ criado era incumbido de ler para o patrão, na hora do desjejum, como uma de suas muitas obrigações domésticas. A leitura de salão reunia grupos de amigos, numa intimidade preservada, convertendo-se em um dos elementos essenciais da sociabilidade. Com tantas alterações nas práticas individuais e sociais de leitura, o "comércio do livro tornou-se comércio social, oportunidade de encontros, ocasião de galante proximidade entre jovens leitores e leitoras"

Vê-se que as práticas da leitura foram variadas no tempo. Atualmente, tem-se uma cultura caracterizada pela rapidez e pela lógica utilitária, o que vai exigir uma prática com maior caráter de funcionalidade, velocidade e simultaneidade.

Lê-se, por exemplo, sentado em frente de uma tela de computador, coordenando olhos que perscrutam as letras, mãos que clicam e controlam o fluxo da leitura, a audição sincronizando o ritmo das informações, o que nem sempre é possível, pois a velocidade do nosso cérebro é limitada e quanto mais informações disponíveis, mais remota a possibilidade de processá-las ${ }^{7}$. Por outro lado, lê-se, escreve-se e conversa-se em salas de bate-papo, ou seja, no espaço virtual da internet.

O objetivo deste texto é ampliar a discussão para outras dimensões do espaço de leitura. 
Ainda que a proposta insira-se na categoria do espaço da leitura, necessário se faz dizer que espaço é apenas um dos elementos que compõem a abrangência do processo de ler e produzir sentidos.

\section{LEITURA COMO ATO DE PRODUÇÃO DE SENTIDOS}

As concepções e as práticas de leitura têm variado ao longo da história. De ato simples de decodificação mecânica de sinais, de hábito, de recepção passiva de mensagens, inequivocamente estabelecidas, a leitura passou a ser compreendida na contemporaneidade como ato complexo de produção, construção e negociação de sentidos (Escarpit, Chartier, Iser, Barthes, Eco, Pêcheux e Freire, entre nós).

Os estudos da língua sofreram alargamento, na atualidade, ao articularem-se a outros domínios do conhecimento - como a Psicologia, a Psicanálise, a Sociologia -, e deram oportunidade a novos campos de estudo do objeto leitura, numa ação afirmativa e interdisciplinar sobre os signos, a linguagem e o mundo.

Estudos sobre a recepção do texto ${ }^{8}$ resultam, por exemplo, desse desenvolvimento. Uma das grandes contribuições de tal enfoque é o reconhecimento de que o texto passa informações diferentes para leitores diferentes, e que cada leitor, com compreensão diversa, comporta-se como um organismo vivo que instrui e recebe instrução. Nesse processo, o leitor insere suas interpretações ao texto e dele obtém efeitos diversos, constantes e em variados contextos, o que reforça o pensar dialético da comunicação.

No processo da leitura, a relação texto/leitor estabiliza um movimento de ir e vir, corrigindo cada passo da leitura, o que Iser chamou de autocorreção de significados ${ }^{9}$.

O leitor, sob essa ótica, é produtor de sentidos e a verdade não emana mais dos textos, e sim está por ser construída. O texto começa a ser o ponto de interseção entre dois sujeitos, leitor/autor, que se relacionam por meio de outro sujeito, o texto.

Ampliando a questão, é importante considerar que ambos, contudo, são determinados por grupos sociais específicos, cada um representando os componentes ideológicos do seu meio. $\mathrm{O}$ ato de ler não é descompromissado, mas sim responsável pelo processo de socialização. Dentro dessa visão que concebe a linguagem a partir de uma abordagem interacionista, surgem outros estudos que buscam compreender o fenômeno da linguagem não apenas centrado na língua, mas também num âmbito fora dela. $\mathrm{O}$ ponto de articulação entre processos ideológicos e fenômenos lingüísticos é, portanto, o discurso. A linguagem enquanto discurso, e, portanto, o texto enquanto discurso suportado na escrita, constitui um modo de produção social.

A teoria lingüística Análise de Discurso, enunciada por Pêcheux e outros ${ }^{10}$, faz refletir sobre nova concepção de leitura que procura observar o processo de produção do texto, bem como o processo de sua significação, dando ênfase ao leitor como produtor de sentido. A leitura passa a ser vista como
8. ISER, Wolfgang. $\mathrm{O}$ ato da leitura: uma teoria do efeito estético. São Paulo: 34, 1996. 2 v.

9. Ibid., p. 126.

10. LACAZ, Lúcia Maria Marques Gama. Imprensa e poder: resistências possíveis? 2001. Dissertação (Mestrado)-Departamento de Ciências Sociais Letras, Universidade de Taubaté, Taubaté, 2001. 
11. ORLANDI, Eni Pulcinelli. Discurso e leitura. 3. ed. São Paulo: Cortez, 1996. p. 38. (Passando a limpo).

12. ISER, op. cit., p. 51.

13. BRUNER, Jerome. Atos de significação. Porto alegre: Artes Médicas, 1997. p. 11.

14. Ibid., p. 11.

15. MANGUEL, op. cit., $p$. 175-201. o momento crítico da constituição do texto, o momento privilegiado do processo de interação verbal, uma vez que é nele que se desencadeia o processo de significação. No momento em que se realiza o processo de leitura, configura-se o espaço da discursividade em que se instaura um modo de significação específico ${ }^{11}$.

Também não é possível entender a leitura sem a premissa da significação, pois ela se dá como processo de comunicação; portanto, ocorre como ato de relação entre seres, ainda que mediada pelos objetos da escrita. Através da leitura acontecem intervenções no mundo, nas estruturas sociais dominantes e até mesmo na produção de variados textos.

Dessa vertente resulta a dinâmica da leitura e da significação; ler é sempre interação. Assim, a relação texto/leitor ganha primazia. Trata-se da leitura como ato relacional entre texto/leitor, cujo sentido "é o ser constituído do texto na consciência do leitor"12.

O poder de significações atribuído à leitura atrela-se a percepção da própria existência. Esse sentido começa a ser formado na criança, passo a passo, e sofre, evidentemente, influência dos pais e das pessoas que dela cuidam, mas é o impacto da herança cultural mediada pelas pessoas, em todas as instâncias, obviamente, que lhe imputa o sentido de ser no mundo. A idéia de transmissão e transformação da cultura é, portanto, interessante para compreender o próprio sentido socioexistencial da leitura.

A cultura tem caráter constitutivo, e o homem dela participa e nela realiza-se: "nosso meio de vida culturalmente adaptado depende da partilha de significados e conceitos" ${ }^{13}$, enfatiza Bruner. Este cognitivista, ao falar-nos da produção de significados, trata como questão central nos seus estudos a natureza e a modelagem cultural nela envolvida. Para ele, "todas as vozes individuais são abstraídas dos diálogos" ${ }^{14}$.

O ambiente cultural ocorre a partir do convívio que se dá num tempo e num lugar, o qual denominamos espaço objetivo.

\section{ESPAÇO OBJETIVO - O AMBIENTE DA LEITURA}

Manguel dedica um capítulo inteiro de sua obra à relação da leitura com o espaço onde ela se realiza. Diz o autor que "com freqüência, o prazer derivado da leitura depende em larga escala do conforto corporal" 15 do leitor. Em suas pesquisas, utiliza-se das representações - obra de arte e texto literário; por isso, consegue fazer uma trajetória da história social da leitura, oferecendo curiosos testemunhos de suas relações com os ambientes e com a corporalidade do leitor.

O espaço objetivo, o meio real que envolve o leitor durante a leitura - varandas, lugares estranhos -, auxilia não só no conforto do corpo, mas na maneira como o leitor deixa-se envolver pelo texto, criando espaços imaginários.

Ao se falar em espaços de leitura, pode-se induzir a pensar que a questão espaço refere-se, apenas, aos modos de ler num ambiente físico. Espaço de 
leitura, num primeiro momento, se nos apresenta como o lugar, o ambiente destinado ao ato de ler, onde o corpo do leitor presentifica-se. Porém, existem outras compreensões para o sentido do espaço, as quais não se restringem ao físico.

\section{ESPAÇO IMAGINÁRIO}

No contexto da teoria do conhecimento, concebe-se distinção entre espaço concreto e espaço imaginário, o que pressupõe a existência de um espaço interior além do espaço físico, geográfico, objetivo. Está-se falando de um espaço intersubjetivo modulado pelas circunstâncias do texto e do leitor. Aí, neste espaço, insere-se a função do fantástico, do imaginário, o espaço das representações.

O real e o imaginário misturam-se, espaço físico e representativo conectamse, da mesma maneira como ocorre em qualquer ação criadora.

A imaginação é fonte de criação. Pelo imaginário, pode-se conservar imagens num lugar fora do tempo em que a instantaneidade é permitida e fora de um lugar real, propriamente dito. Isto ocorre no ato da leitura em que são possíveis deslocações, sem que o objeto, o personagem, o acontecimento envelheçam ou mudem.

A experiência imaginária é desenhada pelo espaço da experiência concreta, que fornece o esquema de sua realização por meio das ações que nele se operam.

É importante refletir sobre algumas peculiaridades do espaço imaginário, uma vez que interagem no processo de produção de sentidos.

\section{Eufemismo}

Pela formação das imagens decorrentes da leitura, há uma espécie de exorcismo da morte, destituição do poder do tempo e correção da realidade.

Daí, dizer-se de uma característica especial da imaginação, qual seja a do eufemismo, muitas vezes confundido com escapismos: "o que quer dizer que há no homem um poder de melhoria do mundo" 16 e que pode ser potencializado por meio da leitura e da capacidade criadora e reconstrutora que ela propicia.

\section{Interação realidade/imaginação}

Bruner, ao explicar o processo da comunicação, vai apontar para duas dimensões complementares de uma narrativa. A narrativa poderá "ser real ou imaginária sem perder seu poder como história. Quer dizer, o significado e a referência da história guardam um relacionamento anômalo entre si" ${ }^{17}$, ou seja, a seqüência de suas sentenças e não a verdade ou falsidade de quaisquer dessas sentenças é o que determina sua configuração geral ou enredo. Esta premissa
16. DURAND, Gilbert. As estruturas antropológicas do imaginário. Lisboa: Editorial Presença, s.d., p. 277.

17. BRUNER, op. cit., p. 47. 
da comunicação é percebida na leitura e acentua-se em determinadas formas de narrativas. Dependendo do texto há maior ou menor grau da participação imaginativa do sujeito durante a leitura.

O texto ficcional é o correspondente escrito da narrativa imaginária. Ao falar sobre ele, Iser expõe questão semelhante à enunciada por Bruner, quando diz que não há oposição entre ficção e realidade, pois não existe nelas uma relação entre seres, mas sim em termos de comunicação. "Como estrutura comunicativa conecta à realidade um sujeito que, por meio da ficção, se relaciona a uma realidade" ${ }^{18}$. A ficção organiza, portanto, a realidade, e não se confunde com aquilo que organiza, e sua função cumpre-se na mediação entre sujeito e realidade.

\section{Criação/Irrealização/Experiência}

É interessante, ainda, uma compreensão sobre a questão da imagem que também acompanha a experiência da leitura.

É pela imagem que se representa o que não se pode ver. Por meio dela reproduz-se o que não se manifesta na verbalidade do texto, mas que também não constitui invenção do leitor. Ela é, então, a categoria básica que se refere ao ausente, ao não-familiar. É diferente da percepção ótica, que conta com a presença do objeto. As representações durante a leitura não tornam visíveis os personagens do texto, pois eles sofrem de pobreza ótica: as imagens apenas refazem os personagens como portadores de significação e não como objetos. Além disso, é uma imagem possível de ser modificada por outra, pois está sempre em ação e aquilo que simboliza é de natureza afetiva.

Por ser transitória e possuir natureza afetiva, a imagem dimensiona a relação do texto/leitor fornecendo dados sobre o grau de interpretação da subjetividade do leitor na representação da imagem e desta sobre o leitor que, nesse sentido, está sendo afetado por uma representação que presentifica algo ausente. É a experiência da irrealização durante a leitura. Durante o processo de leitura isola-se, por um período indeterminado, do mundo real; somente depois que a leitura acaba, o leitor vê-se despertado para o mundo real, o que configura uma fuga, propriamente dita, da realidade, mas sem a possibilidade de descobrir um mundo como uma realidade passível de ser observada. Desse modo, o sentido produzido no texto pode tornar-se experiência, pois nele mesclam-se sujeito e objeto.

Há formas diferentes que estabelecem a constituição da representação entre os tipos de textos. No texto literário, a imagem ocorre como manifestação do objeto imaginário; no texto não-literário, como expressão do objeto existente, porém, ausente. Neste caso, a representação presentifica a ausência e sua forma depende de conhecimentos anteriores acerca dos objetos ausentes. 
oriundas do ato criativo, sendo que este se atrela ao repertório de significações do sujeito leitor.

\section{Ligação entre o excepcional e o comum}

O cotidiano é formado por cânones que focalizam o previsível, o uso comum na condição humana. Mesmo assim, percebe-se que a narrativa, ainda que dotada de legitimidade para perpetuar a canonicidade, é capaz de interpretar o incomum, o excepcional, abrindo brechas para o que não é comum e renegociando significados já consagrados. Afinal, "a viabilidade de uma cultura é inerente à sua capacidade para resolver conflitos, explicar diferenças e renegociar significados comuns" 19 .

O texto escolhe e reorganiza os elementos da fala, colocando-os à disposição do leitor e, dessa forma, esses elementos são atualizados e seus sentidos, renegociados. O texto, em si, tem algumas perspectivas definidas constituídas pelo autor, pelos personagens, pelo enredo e pelo leitor implícito. Mas nenhuma dessas perspectivas define, por si só, o sentido do texto, apenas marca de forma diferente os centros de orientação da leitura. Propriamente dito, "o sentido do texto é apenas imaginável, pois ele não é dado explicitamente; em conseqüência, apenas na consciência imaginativa do leitor" ${ }^{20}$. Isto acontece porque no processo da leitura os atos de imaginação sucedem-se por serem suscitados a modificar, constantemente, o ponto de vista do autor.

Como os sentidos podem ser negociados, por meio da leitura de textos obtêm-se, constantemente, novas e múltiplas produções de sentidos que se oferecem à modelagem social, mas ao mesmo tempo modelados pela prática social.

\section{Dramaticidade}

Trata-se da capacidade de transitar entre dois mundos, o canônico e o idiossincrático dos desejos, crenças e esperanças. Nesse trânsito, o texto empresta estabilidade ao cotidiano e configura-se como parte do ato de significação, pois este se liga à propensão humana de partilhar histórias, fantasiar experiências, imaginar a realização de desejos.

Como estruturador e organizador do mundo do leitor, o texto fornece esquemas que favorecem a construção do mundo, a caracterização de seu fluxo e a segmentação dos eventos dentro deste mundo, o que vai permitir a constituição da memória social. Se não fosse assim, "estaríamos perdidos na escuridão de uma experiência caótica e, provavelmente, de qualquer modo não teríamos sobrevivido como espécie" ${ }^{21}$.

No ambiente real, o sujeito interage com coisas e fatos formando suas estruturas imaginativas, que estão constituídas nas dimensões afetivas e sociais do sujeito. Por isso, diz-se também que a memória liga-se às questões da imaginação e que, portanto, se debruça sobre a categoria do espaço.
19. BRUNER, op. cit., p. 48

20. ISER, op. cit., p. 75.

21. BRUNER, op. cit., p. 54. 
comunicação \& educação • Ano XII • Número 1 • jan/abr 2007

\section{ESPAÇO DE LEITURA COMO MATERIALIDADE DA MEMÓRIA SOCIAL}

A memória é entendida a partir do confronto de diferentes pontos de vista que ajudam não só a lembrança, mas igualmente as formas de ver, observar e analisar no presente fatos ou experiências já vivenciados. É entendida também como a dialética entre o individual e o social. O indivíduo desloca-se do seu mundo individual para o social, e vice-versa. Esse deslocamento permite o contato do ser humano com o mundo. É nessa trajetória que se estabelece o sentido existencial.

A memória conserva para além dos acontecimentos, graças a um conjunto de imagens por ela retido; daí sua espacialidade. O imaginário é do domínio do tempo, mas ainda é "acto de resistência da duração à matéria puramente espacial e intelectual" ${ }^{22}$, uma vez que a estrutura do imaginário é fornecida pela experiência do sujeito, num espaço real que interage com os acontecimentos, coisas, objetos e pessoas, e fundamenta a representação da experiência.

Pode-se inferir que o espaço também é do domínio da memória. A memória, tanto quanto a imaginação, utiliza-se de eufemismos para organizar esteticamente as recordações. Pode-se dizer de uma memória afetiva que ela seleciona acontecimentos ou coisas para as lembranças pelo critério do apego a certas experiências. Essas recordações aparecem maquiadas, escondendo os ultrajes do tempo. A nostalgia da experiência é, portanto, uma nostalgia de ser, emoldurada pelos retoques que o meu afeto exige:

É essa saudade enraizada no mais profundo e no mais longínquo do nosso ser que motiva todas as nossas representações e aproveita todas as férias da temporalidade para fazer crescer em nós, com a ajuda das imagens das pequenas experiências mortas, a própria figura de nossa experiência essencial ${ }^{23}$.

Aí se encontra, provavelmente, a explicação para o fato de que as recordações de leituras venham sempre acompanhadas de uma ambientação, na qual leitor, personagens, coisas, objetos e espaços interagem.

Os ambientes são orientações ao sujeito; assim, as casas da infância e da juventude vêm privilegiadas como lembranças. Por isso, as histórias particulares de leitura registram-nas. Alguns leitores relembram de suas leituras na varanda da casa da avó ou em lugares estranhos como na cozinha, fazendo almoço, ou na cama. Os ambientes onde a socialização, em sentido mais amplo, acontece, como escolas, casas de amigos, clubes e bibliotecas, aparecem como lembranças depois das casas familiares.

Nesse particular, aponta-se a significação ontológica da memória de revelar à pessoa uma maneira peculiar de escolher-se a si própria.

O conjunto de lembranças revela até mesmo a construção social do próprio

22. DURAND, op. cit., p. 275.

23. Ibid, p. 276. grupo no qual o indivíduo insere-se, visto que este não daria conta de remontar sozinho um percurso de acúmulo e articulação de experiências. 
A memória é enxergada na intersecção sujeito/cultura, o que amplia sua propriedade estática de conservar informações, imputando-lhe um certo dinamismo, exigência própria para a ação de reconstrução das experiências passadas, já que é esta uma das formas encontrada pela sociedade para pensar a si própria, mesmo que seja por meio da sua relação com o passado. A memória tem a ver com identidade, pertencimento, com o fluir da vida social. Portanto, é menos um mecanismo de recepção e armazenamento de experiências e mais um processo dinâmico e interativo que se desenrola no cotidiano do homem social, por meio do processo comunicacional. Nessa interação, preenche-se o espaço entre a realidade objetiva e a subjetividade. Nesse movimento, ocorre um diálogo entre símbolos que fazem parte da cultura de muitos sujeitos, levando-os a expressar como se percebem, como participam da cultura, e como se constroem em suas identidades.

Sabe-se que a memória liga-se à cultura e imuniza o organismo coletivo contra a desordem da agressão. Ela é uma espécie de guardiã da integridade de um nós, que garante a sobrevivência de um grupo pela partilha entre indivíduos que são comuns. Dessa maneira, opera como corpo, para fazer passar de ontem para hoje o corpus de conhecimentos, valores ou experiências que consolidam a identidade de um grupo. Sobre ela, Debray vai dizer: "Transmite-se o fogo sagrado, o capital cultural ou simbólico, o patrimônio, o que deve assimilar o trigo que leveda para que o pão conserve seu gosto" ${ }^{24}$.

Conservar o gosto, manter pulsando a vida em sociedade implica na atualização dos quadros sociais, o que só é possível pelo reconhecimento e reconstrução de lembranças articuladas entre si. Memória, enquanto acervo de lembranças, não é um mero produto resultante do acúmulo de vivências, mas um processo que se faz no presente para atender às necessidades do presente. Esta característica permite sua reconstituição de maneira distinta do fluxo das vivências, o que ocorre a partir da localização espaço/tempo que o grupo define.

Nesse sentido, vê-se que a leitura presta-se à organização do mundo particular do sujeito, designando a materialidade da memória social, ao mesmo tempo que é memória individual do próprio leitor.

Sob esse ângulo, a construção da memória do sujeito leitor passa, igualmente, pela noção do seu corpo presentificado no ato da ler.

Espaço e corpo, portanto, são outros elementos articulados na prática da leitura. Visto que o corpo do leitor ocupa um espaço, fica claro que há relação entre corpo do leitor e texto.

\section{O CORPO DO LEITOR NO ESPAÇO DA LEITURA}

A relação corporal estabelecida com o texto é condição da expressão do sujeito e da sua própria maneira de constituir-se em leitor. A leitura pode ser percebida como prática de produção de uma ação. Anotações, entre outros,
24. DEBRAY, Régis. Transmitir: o segredo e a força das idéias. Petrópolis: Vozes, 2000. p. 19. 
poderão complementá-la, e não deixa de ser uma exigência de criar um espaço particular na leitura para a manifestação da expressão do leitor, que dialoga com o texto. Outro espaço requerido e que se articula com o anterior diz respeito à capacidade inventiva para criar ou produzir outros textos, o que de certa forma dá novo sentido à leitura, como o de circularidade, por exemplo: leio e crio para ser lido e compreender o mundo. Outra questão a considerar refere-se ao movimento do corpo durante a leitura e que pode articular-se com outras formas de linguagem, como a gestual.

O corpo manifesta-se na leitura pela forma, pelo movimento e pelos sentidos. Corpo em ação no ato de ler. Daí se dizer de uma morfologia do corpo que lê e também de uma sensualidade da leitura que passa pela ausência ou pela presença do corpo de um outro.

\section{Morfologia do corpo}

A leitura ocorre em determinado espaço e é uma ação que prioriza certos ambientes para se realizar com maior conforto. $\mathrm{O}$ corpo nesta atividade cria uma morfologia própria para a leitura: ler deitado, na privacidade dos gestos, no quarto de dormir, com o corpo ligado, ou não, ao do outro; ler acomodado, solitariamente, numa cama; ler em varandas, no aconchego familiar; ler em pé, parado ou andando; sentado em cadeiras ou poltronas; a leitura sempre passa pela forma do corpo, que se amolda na interação texto/leitor.

Nesse sentido, fala-se que para determinados tipos de texto deve-se dar uma forma especial ao corpo: "há livros que leio em poltronas e livros que leio em escrivaninhas; há livros que leio em metrôs, bondes e ônibus. Acho que livros lidos em trens têm algo da qualidade dos que leio em poltronas, talvez porque em ambos os casos posso me abstrair facilmente do ambiente" ${ }^{\text {25 }}$.

O corpo, nesses casos, indica uma postura de maior ou menor atenção dada ao conteúdo da leitura.

A postura do corpo durante a leitura é auxiliada pelo mobiliário que facilita os diversos propósitos dela. Para as leituras descontraídas, uma cama confortável, uma poltrona, uma almofada serão suficientes. Para as mais reflexivas, uma escrivaninha vai auxiliar nas anotações necessárias e na atenção requerida.

Estas observações deixam perceber que os ambientes formais de leitura devem incluir em seus planejamentos móveis apropriados para suas práticas, tendo em vista que não só a forma do corpo altera-se durante a leitura, mas o próprio leitor busca para cada tipo de leitura uma postura que lhe facilite a relação com o texto.

O corpo modela-se no ato da leitura, é o que foi dito até aqui. O corpo também sente no ato de ler, é o que se vai dizer; sente a ausência do corpo de um outro ou sente a presença do outro que corporifica a leitura. São formas

25. MANGUEL, op. cit., p. 178. diferenciadas da sensualidade. 


\section{Sensualidade e leitura}

A relação que o sujeito leitor estabelece com a leitura ocorre, inicialmente, pela experiência do sensível: olhos, toques, e por que não o cheiro e o som? Essa relação pode acontecer solitariamente, pela ausência do corpo de um outro. Neste caso, a leitura é ato solitário sem, contudo, perder sua condição comunicativa, pois mesmo assim há troca de experiências entre sujeitos.

\section{O corpo ausente}

A leitura como relação entre sujeitos estabelece-se entre um real (leitor) e outro virtual (autor). Apenas com tal afirmativa pode-se depreender o título que encabeça este tópico: leitura como relação que se instaura com um corpo ausente. Mas não é só isto que se quer.

A leitura como ato que se realiza no âmago da solidão, como a ela referia-se Proust ${ }^{26}$ em seu texto intitulado Sobre a Leitura, convida a uma reflexão menos simplista sobre a questão.

Ler solitariamente, na intimidade, entre lençóis enlaçados ao corpo, num clima de sensualidade permitida, tem sido uma imagem constante dos depoimentos de leitura que, de certa maneira, se oferecem para o entendimento de suas práticas, as quais se tornaram privativas na Idade Moderna. Também se associa a sublimação.

A intimidade criada entre o leitor e a leitura expressa uma contingência do sujeito leitor, no caso a da sublimação dos desejos. Fragmentos das falas de muitos leitores dão indício do desejo de suplantarem-se as limitações e os sofrimentos ditados pela dimensão dos sentidos. Aliás, esta parece ser uma busca daqueles que se impõem os caminhos da intelectualidade. Não raro, vêse o intelecto como uma condição para superação dos aspectos sensoriais. Daí se falar em sublimação.

Manguel oferece uma série de testemunhos de relações com a leitura, salientando que "ler na cama fecha e abre ao mesmo tempo o mundo ao nosso redor" ${ }^{27}$. Fecha porque cria um espaço estritamente individualizado, íntimo, que prescinde da presença do outro.

Quando se coloca a questão da ausência do corpo do outro na leitura, recorrendo-se à noção de sublimação, insere-se uma condição de superação dessa ausência, que se dá na esfera de um corpo simbólico, representativo na voz de quem enuncia o texto. Ocorre que nesse âmbito estabelece-se uma relação corpo a corpo, entre o corpo representado e o corpo concreto do leitor. Essa relação incita no leitor reações corporais provocadas pelas mais variadas emoções sentidas no ato da leitura, tais como medo, prazer, tensão, expectativas, ansiedade, angústia, dor, alegria, prazer, êxtase e outras tantas. Há, pois, uma sincronicidade entre corpos (do texto/do leitor), que se instala a partir de uma ressonância dos sentidos.
26. PROUST, Marcel. Sobre a leitura. 2. ed. Campinas: Pontes, 1991. $60 \mathrm{p}$. 27. MANGUEL, op. cit., p. 175. 
Não há, pois, como superar as limitações dos sentidos nem mesmo a erotização da leitura, pois que toda interação texto/leitor atua sobre o corpo.

\section{Leitura pelo corpo do outro}

A experiência da comunicação em leitura pode ocorrer quando se lê a partir do outro; quando este outro é mediador entre texto e leitor e articula a fala ao escrito. Está falando-se do contar histórias, que passa pelos sentidos de quem as ouve e de quem as conta.

Ouvir histórias aponta para algo muito importante: numa comunicação há sempre uma interação de elementos verbais e não-verbais. Esses elementos facilitam a compreensão e a produção do discurso e configuram-se como uma intenção de fala e de formação de sentidos. Quem ouve uma história lembrase das caretas e das diferentes entonações de voz dadas aos personagens pelo contador. Nesse ato de comunicação utiliza-se um código de caráter plástico. São gestos, expressões faciais, posições corporais.

A prática de contar histórias envolve duas situações que, geralmente, se confundem. Pode-se contar histórias transmitindo-se um texto pela voz. Neste caso, o texto mantém-se inalterado; lê-se um texto em voz alta, que é interpretado por quem lê, o que vai estabelecer uma interação entre o oral e o escrito. Esta prática é chamada de reconto.

Pode-se, ainda, inventar histórias ou dar uma interpretação própria para alguma já conhecida. Esta experiência chama-se contação. $\mathrm{O}$ primeiro caso "remete à língua escrita enquanto que a contação de histórias remete à oralidade" ${ }^{28}$. De modo geral, as práticas de reconto ou de contação de histórias efetuam-se para além da linguagem verbal, em que o corpo do sujeito que conta é também significado pelo corpo do sujeito que ouve, e vice-versa.

Outra modalidade de dizer um texto, ligada também à gestualidade, ao movimento corporal e articulada ao escrito, refere-se à prática da declamação ou recitação de textos. Relaciona-se à leitura de um texto ou à sua recitação de cor, com gestos e entonações vocais apropriados.

Declamar poemas exige gestualidade, como nas histórias que se contam para as crianças. Recitar poemas envolve interação entre linguagens escrita, oral e gestual, e configura-se numa prática da expressão humana na qual interagem as esferas racional e emocional.

O corpo expressa pela voz e pelos movimentos um sentido para o texto.

28. BAJARD, Élie. Caminhos da escrita: espaços de aprendizagem São Paulo, Cortez, 2002. p. 97.

\section{REPENSANDO O ESPAÇO PARA UMA POLÍTICA DE LEITURA}

Como já se disse e vem-se enfatizando, na sociedade contemporânea tudo está em mudança: o trânsito estabelecido entre as palavras ditas e escritas, as formas de se relacionar com o outro, os gestos que expressam as diversas experiências e que auxiliam na comunicação, os lugares da comunicação e da leitura. 


\section{Os espaços de leitura • Angela Maria Barreto}

Pelo exposto, chama-se a atenção para os elementos trabalhados nesta reflexão e que se referem aos espaços de leitura, os quais estão sendo alterados nesta sociedade em que os deslocamentos espaciais intensificam-se e são substituídos pela virtualidade, criando um ciberespaço onde nem sempre a experiência do sujeito é reconhecida.

Viu-se que:

- a leitura ocorre vinculada aos espaços físicos, permeados, ou não, pela sociabilidade, principalmente aos dos convívios familiares, em que os vínculos de afeto se dão;

- o espaço imaginário é um lugar de referência ao sujeito ligado às suas expectativas, valores e crenças, e que fundamenta sua experiência no mundo;

- a conservação do espaço real pelo imaginário é condição da memória, que representa e perpetua a experiência do sujeito, orientando-o num tempo;

- a relação corporal estabelecida com o texto é condição da expressão do sujeito, da sua própria maneira de constituir-se e de constituir o texto, produzindo a leitura.

Assim, estas reflexões podem ampliar discussões e subsidiar políticas de leitura considerando que, principalmente, com as alterações atuais nos modos de ler, o espaço de leitura, também sendo alterado, pode incidir em perdas do caráter socioexistencial da prática da leitura, qual seja o da significação.

Resumo: Apontando para a trajetória das práticas de leitura, esta reflexão enfatiza a categoria do espaço na leitura, estendendo-a para além da compreensão do ambiente físico no qual o ato de ler ocorre. Nesse sentido, mostra-se a diversidade de modos de ler, a singularidade de suas práticas e, ainda, reflete-se sobre questões ligadas ao espaço imaginário, demonstrando a importância dos espaços de leitura - físicos/imaginários - na construção da memória social.

Palavras-chave: espaços de leitura, imaginário e leitura, leitura e memória social.
Abstract: Pointing out to the trajectory of practice of reading, this reflection emphasizes the category of the space in the reading, extending it beyond of comprehension of the physical environment in which the reading happens. In this way, the diversity of manners of reading, the strangeness of its practices are showed and also the questions connected to imaginary space, showing the importance of spaces of reading - physical/imaginary - in the construction of the social memory.

Keywords: spaces of reading, imaginary and reading, reading and social memory. 